\title{
Migración y estrés aculturativo: una perspectiva teórica sobre aspectos psicológicos y sociales presentes en los migrantes latinos en Estados Unidos
}

\author{
Arturo Enrique Orozco Vargas*
}

\section{RESUMEN}

Siendo la migración y el proceso posterior de aculturación fenómenos tan complejos y multifacéticos, el objetivo de este artículo es analizar los factores económicos, sociales, políticos y culturales inmersos en éstos. Para lograr dicho cometido, aquí se examinaron teóricamente distintos estudios empíricos y trabajos existentes relacionados con la experiencia migratoria. A su vez, este artículo describe los principales motivos que llevan a los inmigrantes hispanos a abandonar sus países de origen, además de que se analizan los principales factores relacionados con el proceso de aculturación y el estrés aculturativo que viven los inmigrantes en su estadía en Estados Unidos.

Palabras clave: migración, aculturación, motivos para emigrar, estrés aculturativo, recursos.

\section{ABSTRACT}

Since migration and the resulting acculturation process are such complex, multifaceted phenomena, the aim of this article is to analyze the economic, social, political, and cultural factors involved. To achieve this, the author examines theoretically different empirical studies and papers related to the migratory experience. The article also describes the main reasons why Hispanic immigrants leave their countries of origin, as well as the main factors linked to the acculturation process and the acculturative stress immigrants experience during their stay in the United States.

Key words: migration, acculturation, reasons to emigrate, acculturative stress, resources.

* Doctorante del Programa de Investigación Educativa con Concentración en Desarrollo Humano y Estudios de la Familia, University of North Texas, arturo.orozco@my.unt.edu. 


\section{INTRODUCCIÓN}

Cuando se analiza el fenómeno de la migración, no se pueden soslayar aspectos que tocan lo más profundo e íntimo del ser humano, como sus sueños, logros, luchas, tristezas, frustraciones, angustias y, sobre todo, sus esperanzas. Si a esto se añaden las condiciones socioculturales presentes de manera particular en cada país, la migración se convierte en un fascinante objeto de estudio. Debido a complejidad y cantidad de factores involucrados en ésta, la migración se estudia de manera multidisciplinaria para llegar a un mejor entendimiento de sus efectos. Particularmente, investigadores en las áreas de la psicología, la sociología, la antropología y la historia han hecho aportaciones con las que ha sido posible determinar el impacto de la migración en la vida familiar de los migrantes.

El objetivo de este artículo es analizar teóricamente, desde diversas perspectivas, los factores socioculturales asociados con la migración. De igual manera, se describirá el proceso de aculturación de los migrantes latinos que viven en Estados Unidos. El contenido de este trabajo no da a conocer los resultados de una investigación empírica, sino la revisión teórica de estudios realizados en distintos países, principalmente en Estados Unidos, así como de trabajos existentes en los que se ha investigado el fenómeno migratorio y el proceso de aculturación de la comunidad hispana. Para este cometido, en un primer momento la información aquí vertida señalará las principales semejanzas y diferencias entre la sociedad de origen y la sociedad en la que los migrantes se establecen, comparando, por un lado, las condiciones económicas y políticas y, por el otro, los factores socioculturales e individuales presentes en cada uno de estos dos contextos.

Este análisis permitirá conocer al detalle la influencia de estos elementos en la vida de los migrantes hispanos y sus familias. ${ }^{1}$ Después se analizará el proceso de aculturación, algunos de los principales factores socioculturales presentes en la sociedad receptora, el impacto del estrés aculturativo, así como los recursos y estrategias de superación y adaptación que los inmigrantes adquieren y desarrollan para vencer los obstáculos propios de la aculturación y, por ende, lograr una estadía exitosa en Estados Unidos.

Con la finalidad de presentar una visión general e integral de las distintas comunidades latinas residentes en Estados Unidos, se revisaron estudios que incluían la

\footnotetext{
${ }^{1}$ Aunque el término "hispano" fue acuñado por organismos federales estadunidense para describir las características de las personas provenientes de México, Puerto Rico, Cuba y otros países de Hispanoamérica, muchos autores prefieren el término "latino" por hacer referencia directa a los emigrantes provenientes de un país de América Latina. Debido a que en la bibliografía científica no se hace una distinción específica entre hispano y latino, ambos términos se usarán aquí de manera indistinta.
} 
participación de migrantes provenientes de distintos países de América Latina, no sólo mexicanos. Antes de empezar la descripción de las razones que orillan a los emigrantes a la decisión de abandonar sus países de origen, conviene describir brevemente cada una de las etapas que conforman la historia del proceso migratorio en Estados Unidos. Esta revisión dará cuenta del predominio de la migración hispana durante las últimas cuatro décadas y el porcentaje de familias de ese origen establecidas en Estados Unidos.

\section{CONTEXTO HISTÓRICO DE LA INMIGRACIÓN HISPANA en Estados UnIDOS}

Durante los últimos cuatro siglos, Estados Unidos ha sido un refugio y un lugar muy especial para el desarrollo de muchos grupos de inmigrantes (Daniels, 2002). Entre estos grupos, los latinos no sólo tienen la tasa de inmigración más alta en estos momentos, sino que durante los próximos años ellos constituirán el grupo minoritario más grande en Estados Unidos (Pew Hispanic Center, 2009). Aunque los hispanos, ya sea solos o con sus familias, han emigrado a Estados Unidos desde el siglo XVIII, el movimiento migratorio más grande comenzó a inicios de los setenta. De acuerdo con la mayoría de los historiadores e investigadores, la historia de la inmigración a Estados Unidos durante el siglo xx se divide en tres fases, cada una con características muy distintivas (Durand y Arias, 2000; Gonzalez, coord., 2000).

Aunque cada autor ha usado diferentes sistemas de clasificación, el propuesto por Massey (1995) incluye a la mayoría de los demás. En su clasificación, Massey denomina a la primera etapa como la era clásica (1901-1930). Estas décadas estuvieron caracterizadas principalmente por la inmigración europea. Durante esta etapa, el porcentaje de inmigrantes europeos fue de 79.6 por ciento, mientras que el de inmigrantes latinos fue de sólo 16.2 por ciento. La segunda etapa se denomina "la gran pausa", la cual comenzó en 1931 y concluyó en 1970. Durante este periodo, hubo un cambio muy importante en el porcentaje de inmigrantes hacia Estados Unidos. En estas décadas, el porcentaje de inmigrantes europeos (46.2 por ciento) fue descendiendo hasta equipararse con el de los inmigrantes hispanos (43.6 por ciento) (U.S. Immigration and Naturalization Service, 1994). Este incremento en el porcentaje de inmigrantes latinos tuvo varias causas; sin embargo, el Programa Bracero es considerado un factor determinante en este auge (Verduzco, coord., 2001). Este programa comenzó en 1942 y fue el resultado de negociaciones entre los gobiernos de México y Estados Unidos, con la finalidad de contratar obreros mexicanos para trabajar en granjas y labores del campo, así como en la construcción de vías de ferrocarril durante la segunda guerra 
mundial. No solamente este programa trajo muchos beneficios económicos a los trabajadores y sus familias, sino que también les dio la posibilidad de residir temporal o permanentemente en el país vecino del Norte. Se estima que desde 1942 hasta 1964, lapso en el que estuvo vigente este programa, más de dos millones de mexicanos trabajaron legalmente en Estados Unidos (Rumbaut, 1994).

En la tercera etapa, denominada "el nuevo régimen", se presentó la tasa más grande de inmigración hispana en la historia de Estados Unidos. Estas décadas, desde 1970 hasta el año 2000, se caracterizaron por altas concentraciones de latinos en regiones muy específicas, el número cada vez más creciente de inmigrantes indocumentados venidos principalmente de México y Centroamérica, la incapacidad de integrar al campo laboral a una cantidad excepcional de nuevos inmigrantes, la creciente segmentación del mercado laboral, así como las leyes de inmigración cada vez más restrictivas, particularmente en contra de los indocumentados (Massey, 1995); sin embargo, a pesar de estos y otros muchos obstáculos y desafíos que los hispanos deben sortear, la migración hacia Estados Unidos continúa siendo la mejor opción para ellos y sus familias. Entre 1971 y 1993, el porcentaje de inmigrantes alcanzó su índice más alto con un 49.6 por ciento, lo cual representa 25.9 millones de inmigrantes hispanos. En contraste, el porcentaje de inmigrantes europeos constituyó solamente el 13.1 por ciento (U.S. Immigration and Naturalization Service, 1994). A su vez, durante los noventa, la población hispana pasó de 22.4 millones a 35.3 millones (U.S. Census Bureau, 2001).

A este número hay que añadir la proporción de inmigrantes indocumentados, la cual muchas veces no es reportada en el censo oficial. Organizaciones privadas como el Pew Hispanic Center han estimado que el porcentaje de inmigrantes latinos indocumentados que viven en Estados Unidos se había incrementado un 30 por ciento entre los años 2000 y 2005. Esto dio como resultado un estimado de 8.4 millones en el año 2000 (Hoefer, Rytina y Baker, 2012), mientras que el número de inmigrantes indocumentados hasta el 2005 sumaba alrededor de once millones (Passel, 2005). Reuniendo cifras oficiales y otras proporcionadas por este tipo de organizaciones civiles se estimó que la población hispana (incluyendo inmigrantes documentados, indocumentados, así como los hijos de ambos grupos) en el año 2005 era de 42.7 millones. Tomando las cifras del último censo realizado en Estados Unidos, al finalizar 2012, la población hispana alcanzaría los 53.8 millones (Pew Hispanic Center, 2012). De acuerdo con este censo, la población hispana tuvo un incremento de 35.3 millones en el año 2000 a 50.5 millones en 2010, lo cual indica que alrededor de una tercera parte del crecimiento total de la población hispana se dio durante esta década. Estimaciones basadas en la trayectoria de la población hispana han mostrado que al finalizar 2020 el número de hispanos habrá alcanzado los 60 millones. A su vez, se espera que en 
2050, aproximadamente el 25 por ciento del total de la población en Estados Unidos tendrá un origen hispano.

\section{MOTIVOS PARA EMIGRAR}

Como se dijo en el apartado anterior, el fenómeno de la migración requiere investigar la complejidad de los distintos factores presentes tanto en la sociedad de origen, como en la sociedad receptora. La finalidad de esta sección es describir, por una parte, el contexto sociocultural, político y económico propio de sus comunidades de origen y, por la otra, hacer énfasis en los factores que influyen directamente en la decisión de emigrar hacia Estados Unidos, incluyendo sus rasgos de personalidad, habilidades para interactuar socialmente, características biológicas y la percepción de sí mismos. Todos estos factores en conjunto influyen directamente en la naturaleza y los motivos que las familias e individuos tienen para que, en un momento determinado de sus vidas, tomen la decisión de emprender un largo camino hacia Estados Unidos.

Aunque cada inmigrante tiene un motivo sumamente particular para abandonar su país de origen, investigadores en este campo han identificado algunos factores en común: la tendencia de emigrar hacia países con mejores condiciones económicas (Fassmann y Munz, 1994; Rumbaut, 1994; Simon, coord., 1990) y el deseo de encontrarse y vivir nuevamente con sus familiares y amigos establecidos previamente en el país receptor (Light, Bhachu y Karageorgis, 1993; Massey, 1999). Aquí se describen detalladamente los motivos económicos, políticos, socioculturales e individuales que llevan a los inmigrantes hispanos a tomar la decisión de emigrar hacia Estados Unidos.

\section{Motivos ECONÓmicos}

Estudios en diferentes países han encontrado, de manera consistente, que las condiciones económicas son determinantes en el proceso de emigrar hacia otro país (Bacallao y Smokowski, 2007; Gonzalez, coord., 2002; Rumbaut, 1994). De manera particular, algunos investigadores han señalado que la decisión final de emigrar desde México y otros países latinoamericanos hacia Estados Unidos se vincula con el crecimiento de la agricultura, la construcción y otros sectores económicos que han tenido un gran desarrollo en Estados Unidos durante los últimos años (Browning y Zenteno, 1993; Rivera-Batiz, 1999; Verduzco, 1995). Por ejemplo, en un estudio que incluía la participación de inmigrantes mexicanos de ambos sexos, Chavez, Flores y Lopez (1989) 
encontraron que una de las principales motivaciones que tuvieron estas personas para emigrar de México fue la gran diferencia en salarios. Mientras que en éste necesitarían una semana para conseguir alrededor de cuatrocientos pesos recibiendo el salario mínimo, en Estados Unidos, con sólo trabajar casi cinco horas ganarían la misma cantidad.

De igual manera, la escasez de trabajos bien pagados y estables es otra de las razones más relevantes que muchos de los inmigrantes tienen para abandonar sus países de origen. Estudios realizados en la frontera con Estados Unidos revelaron que 27.5 por ciento de los inmigrantes mexicanos no ha sido capaz de conseguir un trabajo en los meses previos a tomar la decisión de emigrar hacia Estados Unidos (Colef, Conapo y STPS, 1994).

No solamente son los bajos niveles de empleo y la enorme diferencia entre salarios dos de los factores más importantes que constituyen los motivos más fuertes para emigrar, sino también algunas tendencias demográficas en México y sus efectos directos en el empleo se han identificado como las razones al momento de tomar la decisión de emigrar (Dussel, 1997). De manera particular, desde comienzos de los ochenta, México ha sido incapaz de generar las oportunidades de trabajo que se necesitan en los sectores de agricultura y manufactura. Cabe agregar que - a pesar del número de maquiladoras, determinantes en el aumento de empleos, particularmente en los estados de la frontera norte- muchos de los subsectores más tradicionales (automotriz, de producción de textiles y piel, del transporte y el metalúrgico) han sufrido una considerable expulsión de trabajadores (Aspe, 1993; Carrillo, coord., 1993). Por ende, los salarios más altos y las condiciones laborales más estables en Estados Unidos constituyen de manera directa una opción muy atractiva para la mayoría de los inmigrantes hispanos.

\section{El CONTEXTO POLÍTICO EN LA SOCIEDAD DE ORIGEN}

El contexto político en México y otros países latinoamericanos incluye factores legales, locales y regionales (Zolberg, coord., 2006). Si bien es cierto que la mayoría de los migrantes que intentan cruzar la frontera hacia Estados Unidos tienen motivos de carácter económico, a ello deben añadirse las condiciones políticas en varios países de América Latina, que han fomentado la salida de un número indeterminado de inmigrantes y sus familias. Por ejemplo, la inestabilidad política prevaleciente en Centro y Sudamérica en la década de los noventa estimuló una constante inmigración proveniente de estas regiones (Coleman, 2002). De manera particular, durante los años ochenta, los conflictos políticos en Guatemala, El Salvador y Nicaragua fueron 
el principal motivo que tuvieron muchos hombres y mujeres junto con sus hijos para salir huyendo de sus países de origen (Ronstrom, 1989). Como resultado de esta situación, durante esta década en particular el tamaño de la población hispana en Estados Unidos se incrementó un 34.4 por ciento, para llegar a un estimado total de aproximadamente 19.5 millones de latinos que viven en Estados Unidos.

\section{FACTORES Y CARACTERÍSTICAS INTERNAS DE LOS INMIGRANTES}

Con el objetivo de examinar el fenómeno de la inmigración, se han realizado estudios en varias latitudes, los cuales han revelado la fuerte influencia de una gran cantidad de factores externos. Aunado a ello, existe un conjunto de características asociadas a la personalidad que cumplen un papel determinante en la decisión de abandonar sus comunidades de origen y emigrar a otros países. Aunque las condiciones externas influyen en el deseo de emigrar, ciertos rasgos de personalidad hacen la diferencia entre quedarse en el lugar donde se encuentran viviendo o recorrer una larga travesía hasta su destino (Boneva y Frieze, 2001; Dion y Dion, 2001).

En sus primeras investigaciones en esta área, Morrison y Wheeler (coords., 1976) acuñaron el término "personalidad pionera", con la finalidad de describir las características internas de los inmigrantes con un gran deseo de moverse geográficamente. De manera particular, la personalidad de estos inmigrantes se caracteriza por la necesidad de vivir experiencias novedosas y la percepción de que existen mejores oportunidades económicas en otras regiones. Años más tarde, otros estudios revelaron que las personas que ya han inmigrado están más dispuestas a emigrar nuevamente que las que nunca han dejado sus países de origen (Sakkeus, 1994).

De acuerdo con Boneva y Frieze (2001), los inmigrantes que deciden dejar el país donde vivían tienden a ser más perseverantes cuando se trata de alcanzar sus objetivos, poseen una inclinación que los orienta más hacia el trabajo, además de contar con una mayor motivación interna en comparación con quienes deciden permanecer en sus comunidades.

Por otra parte, los migrantes con estos rasgos de personalidad no presentan una orientación tan marcada hacia su familia, lo cual les permite sentirse más libres de tomar la decisión de emigrar. En términos generales, las personas más ambiciosas y más comprometidas con su trabajo están más dispuestas a emigrar (Brett, Stroh y Reilly, 1993). Opuestamente, Frieze, Hansen y Boneva (2006) encontraron que las personas que reportaron altos niveles de apego a la familia y lazos más fuertes con sus amigos tienen más probabilidades de permanecer en su actual lugar de residencia. 


\section{FACTORES SOCIOCULTURALES PRESENTES EN LA SOCIEDAD RECEPTORA}

La siguiente etapa en el proceso de inmigración comienza con la travesía de los inmigrantes hacia una nueva región geográfica, a la cual se ha dado el término de sociedad receptora. ${ }^{2}$ Según Dinesh Bhugra (2004), esta experiencia se caracteriza por eventos positivos o negativos, apoyo emocional y económico, cambios personales, oportunidades, aprendizajes, recursos, obstáculos y desafíos. El propósito de este apartado es describir el contexto sociocultural que encuentran los inmigrantes hispanos a su llegada a Estados Unidos.

\section{ConteXto eCONÓmico-SOCIOCULTURAL}

Los inmigrantes hispanos son considerados un grupo étnico desfavorecido en lo referente a su situación económica, ya que la mayoría no tienen las habilidades que demandan ciertos sectores de la fuerza laboral, viven lejos del lugar donde se encuentran los empleos disponibles, no cuentan con un permiso para trabajar legalmente, son contratados por sólo unos pocos días o tienen muchas responsabilidades familiares. Por estas razones, es más difícil para ellos conseguir un empleo estable y bien remunerado (Wilson, 1996). Además, aunque una gran cantidad de latinos son contratados como fuerza laboral, la mayoría son incapaces de obtener una buena remuneración económica para sostener a sus familias (Durand, Massey y Zenteno, 2001), debido en gran parte al tipo de trabajos que desempeñan, los cuales frecuentemente se relacionan con la agricultura, la industria de la construcción, la textil, la limpieza doméstica y el mantenimiento en edificios, así como la venta de distintos objetos o comida en las calles (Hondagneu-Sotelo, coord., 2001; Ibarra, 2000). No sólo estos trabajos se caracterizan por bajos salarios, falta de sindicatos, explotación laboral y actividades que requieren un gran esfuerzo físico, sino que la mayoría de estos trabajos se desarrollan en regiones geográficas muy pobres (Lin, 1995; Valenzuela, 2001).

Por otra parte, evidencia empírica sugiere que la mayoría de los latinos participa en la economía informal (Williams y Windebank, 1998). Debido a que este tipo de trabajo no se encuentra bajo el control de las instituciones regulatorias, la mayoría de estas actividades se ejecutan sin la inspección de los mínimos estándares de seguridad. De igual manera, muchos de los trabajadores desempeñan actividades que los ponen en peligro de sufrir una lesión (Quesada, 1999; Valenzuela, 2003; Walter et al., 2002).

\footnotetext{
${ }^{2}$ Otros términos usados en las publicaciones científicas para referirse a la sociedad receptora son país receptor o sociedad de residencia.
} 
Aunque los inmigrantes hispanos deben enfrentar innumerables obstáculos en su proceso de adaptación a las condiciones económicas en Estados Unidos, esta situación es incluso peor para las mujeres y para los inmigrantes con un nivel educativo muy bajo o, por el contrario, con un nivel educativo muy alto; por ejemplo, quienes se encuentran en ambos extremos del continuum educativo tienen más dificultades cuando tratan de conseguir un empleo que resulte satisfactorio y apropiado para ellos (Tseng, coord., 2001).

Si tomamos en cuenta el género, factores muy específicos como la dependencia económica, los roles de género tradicionales y los bajos niveles educativos influyen directamente, creando situaciones muy difíciles para las mujeres. Aunque contar con un empleo tendría que ser un elemento que le diera a dichas mujeres mayor poder en el sistema familiar, lo cual a su vez eventualmente redundaría en bajos niveles de estrés psicológico y ansiedad, algunos estudios han revelado que el estatus laboral es un factor de riesgo muy importante para las inmigrantes debido principalmente a la sobrecarga de trabajo (como las responsabilidades en el hogar, la crianza de los hijos y largas jornadas de trabajo). En muchos casos, incluso cuando las mujeres inmigrantes ganan más que su pareja o tienen un nivel educativo más alto, ellas no siempre reciben los mismos beneficios que los hombres (Dion y Dion, 2001).

Como se ha señalado repetidamente, la mayoría de los inmigrantes hispanos residentes en Estados Unidos enfrentan muchas dificultades debido a la inestabilidad de las condiciones laborales (Simich, 2006). Cuando llegan a Estados Unidos, de manera general estos inmigrantes pueden clasificarse en dos categorías: por un lado, los que intentan establecer una residencia permanente y, por el otro, los que emigran a Estados Unidos con un objetivo temporal. Este último grupo incluiría a los trabajadores que responden a las demandas y cambios en las condiciones laborales de cada región geográfica. Después de haber trabajado por cierto tiempo, estos inmigrantes son forzados a regresar a sus países de origen una vez concluida su labor.

Por el contrario, los inmigrantes con la intención de residir permanentemente en el país de destino, comienzan un éxodo interno hacia las áreas con mejores condiciones económicas y políticas. Al encontrarlas, se establecen con sus familias en esas comunidades, mientras las condiciones laborales así lo permitan (Coleman, 2002). No sólo grandes comunidades de latinos se han establecido en las ciudades más pobladas del país, como Los Ángeles, Nueva York, Chicago y Houston, sino que también los latinos se han convertido en el grupo étnico más grande en San Antonio, Miami y en muchas otras ciudades a lo largo de la frontera con México (Massey, 1995). Incluso en estados como California se estima que la población hispana sobrepasará a los caucásicos hacia el 2025, convirtiéndose en el principal grupo étnico en este estado (Purdum, 2000). 
Aunque la mayoría de las familias hispanas han sido capaces de lograr una adaptación exitosa en estas ciudades, el contexto político en Estados Unidos continúa siendo un gran desafío para la mayoría de los latinos. Por ejemplo, el miedo a la deportación es una de las preocupaciones más grandes para los inmigrantes indocumentados, quienes a su vez tienen que enfrentarse al desempleo y otros problemas laborales (Sullivan y Rehm, 2005). Así pues, el miedo a la deportación influye directamente en la percepción de la libertad y la capacidad de involucrarse con otros grupos étnicos (Berry, 2001). En el contexto familiar, el miedo a la deportación tiene un impacto directo en la toma de decisiones relacionadas con la escuela, el lugar de residencia, el apoyo en los servicios médicos y las oportunidades laborales.

\section{FACTORES SOCIODEMOGRÁFICOS}

Aunado a los factores descritos previamente, existe un conjunto de características sociodemográficas, entre las que destacan la edad, nivel educativo, género y región geográfica que nos permiten conocer quiénes y cómo son los inmigrantes hispanos.

\section{Edad}

Aunque algunos niños y adultos mayores acompañan a los migrantes en su viaje a Estados Unidos, cerca de la mitad los migrantes tienen entre veinte y treinta y cinco años de edad (Gonzalez, 2002). Estudios realizados en el 2011 estimaron que el 59 por ciento de los inmigrantes indocumentados tenía entre 25 y 44 años de edad, el 26 por ciento de ellos era menor de 24 años y el 15 por ciento tenía 45 años o más (Hoefer, Rytina y Baker, 2012). De esta manera, incluyendo inmigrantes documentados, indocumentados y los hijos de ambos grupos, el censo más reciente dio a conocer que 14.4 millones de latinos tienen menos de 15 años de edad, 7.9 millones tienen entre 15 y 24 años, 12 millones tienen entre 25 y 39 años, 8.5 millones tienen entre 40 y 55 años y, finalmente, 5.8 millones tienen 56 años o más (U.S. Census Bureau, 2011).

\section{Educación}

Respecto de la educación, se estima que, en promedio, los inmigrantes mexicanos residentes en Estados Unidos han completado nueve años de educación escolarizada; esto significa que dejaron la escuela cuando eran adolescentes (Gonzalez, 2002). En 
una investigación cuyo objetivo fue estudiar la adaptación de las familias en el proceso posinmigratorio, los padres que participaron comentaron que, además de conseguir un mejor trabajo, habían emigrado para darle a sus hijos mejores oportunidades incluyendo el acceso a la educación en Estados Unidos y la posibilidad de aprender el inglés y hablarlo con fluidez (Bacallao y Smokowski, 2007). Tomando en cuenta las cifras oficiales, el censo más reciente mostró que el 62.9 por ciento de latinos se clasificaron como "graduados de preparatoria", en comparación con los caucásicos, quienes alcanzaron el 87.6 por ciento. Entre estos latinos, los de origen cubano fueron el grupo más grande con un 81.4 por ciento, seguido por los puertorriqueños, que obtuvieron un 74.8 por ciento, y los mexicanos con un 75.4 por ciento. Hasta este nivel educativo, la diferencia entre latinos y otros grupos étnicos no es muy significativa; sin embargo, el nivel educativo de los latinos disminuye considerablemente cuando se los clasifica como "graduados de nivel superior o más". En comparación con 52.4 por ciento de los asiáticos o el 30.3 por ciento de los caucásicos, solamente el 13.9 por ciento de los hispanos alcanza este nivel (U.S. Census Bureau, 2011).

\section{Género}

El número de mujeres y hombres hispanos es muy equitativo: 25.2 millones de hombres y 23.4 millones de mujeres (U.S. Census Bureau, 2011). En 2011, se estimó que el 53 por ciento de los inmigrantes indocumentados eran hombres (Hoefer, Rytina y Baker, 2012).

\section{Factores geográficos}

La distancia entre el país de origen y Estados Unidos es un elemento muy importante para los inmigrantes cuando deciden dejar sus comunidades. Esto llega a ser muy evidente al observar la proporción de inmigrantes, tomando en cuenta el país de origen. De acuerdo con el censo de 2010, 50.5 millones de latinos viven en Estados Unidos, de los cuales 3998280 provienen de Centroamérica y 2769434 vienen de Sudamérica. Por otra parte, 31789258 son de origen mexicano, lo cual representa el 63 por ciento del total de la población hispana viviendo en Estados Unidos (U.S. Census Bureau, 2011). 


\section{ADAPTACIÓN SOCIOCULTURAL}

Como ha sido descrito en las secciones anteriores, los factores económicos, políticos y sociodemográficos, así como los rasgos de personalidad de los inmigrantes influyen directamente en el proceso de adaptación a una nueva cultura. Una gran cantidad de estudios empíricos han documentado cómo los inmigrantes necesitan no sólo aprender otras costumbres, leyes, lenguas, formas de interacción social, sino que también necesitan adaptar sus ideas, sentimientos y comportamientos a las normas de la sociedad en la que se establecen (Negy y Woods, 1992).

Como se señaló anteriormente y lo han sustentado investigadores y teóricos del fenómeno migratorio, el proceso de aculturación es influido por factores presentes en el contexto social (por ejemplo, características de la sociedad de residencia, idioma, diferencias culturales, separación de la familia, inestabilidad económica y política en la sociedad de origen, la habilidad para aprehender un nuevo sistema cultural y el apoyo social que reciben), así como variables individuales (rasgos de personalidad, nivel educativo, costumbres culturales, autoestima, tradiciones y los roles de género) que se encuentran antes y durante el proceso de inmigración (Arbona et al., 2010; Bhugra, 2004; Carballo, coord., 1994; Kosic, 2004; Parrado y Flippen, 2005).

En términos generales, estudios a nivel internacional han confirmado que la adaptación a un nuevo país es más difícil para los inmigrantes cuando existen importantes diferencias culturales entre la sociedad de origen y la nueva sociedad receptora (Horenczyk, 1996). Por otra parte, para lograr una adaptación exitosa, los inmigrantes tienen que ser capaces de establecer relaciones cordiales y significativas con el grupo huésped y, al mismo tiempo, desarrollar un conjunto de actitudes positivas que les permitan una convivencia respetuosa (Kosic, 2002).

El término adaptación sociocultural ha sido propuesto para describir el proceso cultural a través del cual los inmigrantes son capaces de establecer relaciones constructivas en una nueva cultura (Maydell-Stevens, Masgoret y Ward, 2007). La diferencia entre una adaptación exitosa o el fracaso en este proceso depende de los ajustes que realicen los inmigrantes cuando éstos se encuentran ya viviendo en su nuevo lugar de residencia (Torres y Rollock, 2004). En términos generales, la calidad de la adaptación sociocultural estará determinada por los recursos que obtengan, incluyendo las oportunidades escolares, salarios, fluidez en el idioma, apoyos gubernamentales y las interacciones sociales dentro de la comunidad receptora (Ward, 2004). Mientras que algunos inmigrantes se ajustan rápida y satisfactoriamente a la nueva cultura, quienes de manera especial tienen un fuerte arraigo a su comunidad de origen encuentran muchas barreras en esta transición (Yeh et al., 2003). 


\section{ACULTURACIÓN}

Derivado de estos ajustes socioculturales, la tercera etapa en el proceso de inmigración es la adaptación propiamente al estilo de vida en el nuevo país receptor (Espin, 1987). De acuerdo con Bhugra (2004), esta etapa se caracteriza por el estrés, el choque cultural, las dificultades económicas que la mayoría de los inmigrantes experimentan, la discrepancia entre sus aspiraciones y los logros ya alcanzados, la sensación de desarraigo y la discriminación. Después de haber comenzado a ajustarse a la nueva cultura, muchos de los inmigrantes transitan por un proceso posterior de adaptación o aculturación. El término “aculturación" fue propuesto por Redfield, Linton y Herskovits en 1936 para describir el fenómeno mediante el cual grupos de individuos provenientes de distintas culturas establecen interacciones de primera mano. Estas interacciones generarán cambios sucesivos en los patrones culturales, tanto en los inmigrantes como en los individuos ya establecidos en la sociedad de residencia. Así, al hablar de aculturación, conviene enfatizar los numerosos cambios hechos por los inmigrantes y sus familias (Adelman, 1988; Berry, 1980; George y Ramkissoon, 1998; Kosic, 2004; Melville, 1978; Shin, 1999; Yeh et al., 2003).

El proceso de aculturación ha sido estudiado por infinidad de investigadores desde distintas disciplinas, como la antropología, psicología, sociología, salud pública, educación y economía. En el pasado, se propusieron diferentes modelos con la finalidad de examinar esta experiencia. Entre los más reconocidos, el modelo bidimensional ofrece una descripción integral respecto de la adaptación sociocultural y psicológica que viven los inmigrantes. El más representativo de estos modelos bidimensionales de aculturación fue propuesto por Berry para señalar el proceso de adaptación a la nueva cultura y los desafíos que éste representa (Berry, 2001). El modelo bidimensional consiste en cuatro estrategias de aculturación usadas por los inmigrantes en su proceso de adaptación a su nuevo lugar de residencia (Berry, 1997). A su vez, estas estrategias se derivan de dos orientaciones generales: la primera está caracterizada por la preferencia que los inmigrantes tienen por mantener su identidad y herencia cultural. La segunda orientación enfatiza la preferencia de los inmigrantes por participar y tener un contacto cercano y continuo con otros grupos étnicos, quienes ya se encuentran establecidos en la sociedad de residencia. Así es como estas dos orientaciones producen cuatro tipos distintos de estrategias (asimilación, separación, marginación e integración) cada una de éstas con características muy particulares:

- Integración. Es la estrategia por medio de la cual los inmigrantes mantienen actitudes positivas hacia su cultura de origen y al mismo tiempo establecen interacciones cercanas y significativas con los miembros de la sociedad de residencia. 
Según esta estrategia, mientras se sienten aceptados por los miembros de la nueva cultura, los inmigrantes mantienen viva su cultura original (Moghaddam, Taylor y Lalonde, 1987). Estudios han revelado que no solamente la integración es lo más recurrente entre los grupos minoritarios, sino que los inmigrantes que escogieron esta estrategia de aculturación experimentaron menores niveles de estrés aculturativo en comparación con los inmigrantes que prefirieron la asimilación, separación o marginación (Bochner, 1982; Zheng y Berry, 1991). A su vez, la integración ha sido relacionada con niveles bajos de depresión en los inmigrantes (Beiser et al., comps., 1988; Berry et al., 1989). Otros estudios han mostrado que la integración fue considerada por los inmigrantes como la mejor estrategia para lograr una adaptación psicológica exitosa (Ward y Kennedy, 1994).

- Asimilación. Es definida como la interacción con individuos pertenecientes a otro grupo étnico y el rechazo a mantener su propia identidad cultural. Estudios han encontrado que los inmigrantes con más similitudes culturales con los miembros de la sociedad de residencia y reportan altos niveles de autoestima prefieren la asimilación como la mejor estrategia de aculturación (van Oudenhoven, Willemsma y Prins, 1996).

- Separación. Ésta se presenta cuando los individuos mantienen su cultura original y al mismo tiempo evitan interactuar con otros grupos, particularmente con los pertenecientes a la sociedad receptora. Aunque algunos investigadores han enfatizado la importancia de identificarse con los valores de su propia cultura, lo cual trae consigo una alta autoestima y un sentido de identidad (Hewstone y Brown, comps., 1986; Phinney, 1990), en contraste, otros estudios han mostrado que la estrategia de separación está asociada con altos niveles de estrés y con bajos niveles de adaptación sociocultural (Berry et al., 1987; Ward y Kennedy, 1994).

- Marginación. Definida como el mínimo interés por mantener la cultura de origen (frecuentemente debido a la pérdida cultural obligatoria), así como la ausencia de interacciones con los miembros de la nueva cultura (frecuentemente debido a la exclusión o discriminación). En un estudio, incluyendo la participación de inmigrantes polacos y croatas que residen en Italia, la marginación estuvo asociada con bajos niveles de adaptación psicológica y sociocultural (Kosic, 2002).

De acuerdo con Berry (1997), la decisión de elegir entre una u otra de estas estrategias dependerá de los distintos factores descritos hasta aquí. El dinamismo de estas cuatro estrategias de aculturación hace posible que algunos opten por una y mantengan esa elección por el resto de sus vidas; por el contrario, otros inmigrantes pueden adquirir una y al cabo del tiempo deciden que es otra la más conveniente para ellos. 
De esta manera, el impacto que cada estrategia tiene sobre la vida de los inmigrantes y sus familias varía dependiendo de estas elecciones.

Hecho el análisis de los factores asociados con el proceso de aculturación y las distintas estrategias para alcanzarlo, en el siguiente apartado se describirá en particular un elemento clave para entender con exactitud lo complejo y difícil que es este proceso para los millones de inmigrantes hispanos que residen en Estados Unidos.

\section{ESTRÉS ACULTURATIVO}

Por el gran impacto y las consecuencias negativas que surgen de éste, es importante y necesario analizar el nivel de estrés presente en los inmigrantes y sus familias. En varios estudios se han enfatizado los altos niveles de estrés que experimentan los inmigrantes en este largo proceso (Al-Issa, 1997; Arbona et al., 2010; Bacallao y Smokowski, 2007; Berry, 2001; Bhugra, 2004; Boneva y Frieze, 2001; Garcia y Lindgren, 2009; Kosic, 2002; Negy y Woods, 1992; Neto, 2002; Parrado y Flippen, 2005; Torres y Rollock, 2004). Estudios a nivel mundial han mostrado cómo los inmigrantes tienen más probabilidades de experimentar altos niveles de estrés cuando las habilidades y métodos que están empleando en su adaptación a la nueva sociedad no producen los resultados que esperan (Torres y Rollock, 2004).

De manera particular, algunos estudios que incluyen la participación de inmigrantes hispanos han mostrado que factores como el miedo a la deportación, la discriminación, la falta de dominio del inglés, el estatus migratorio y la separación de la familia están fuertemente relacionados con altos niveles de estrés familiar (Arbona et al., 2010).

En términos generales, los causantes de estrés relacionados con la inmigración conllevan elementos socioculturales, económicos y psicológicos. Caplan (2007) clasificó estos factores causantes de estrés ${ }^{3}$ en tres categorías: 1) estresantes interpersonales; 2) estresantes instrumentales y ambientales y 3) estresantes sociales. A continuación se describirán las principales características y sus implicaciones en la vida de los inmigrantes hispanos.

En lo que respecta a los estresantes interpersonales, éstos se caracterizan por cambios en los roles de género, el funcionamiento familiar, conflictos intergeneracionales, así como la pérdida de apoyo social y familiar. Evidencia empírica sugiere que la mayoría de los inmigrantes experimentan niveles altos de angustia cuando emigran

\footnotetext{
${ }^{3}$ El término "estresante" (stressor en inglés) ha sido usado de manera recurrente en la bibliografía científica para describir las experiencias, sucesos o circunstancias que provocan tensión, ansiedad, estrés o preocupación excesiva, en este caso particular en los migrantes hispanos.
} 
solos, con la finalidad de conseguir un trabajo que les permita crear las condiciones necesarias para que más adelante los miembros de su familia se reencuentren y vivan nuevamente con ellos (Bhugra, 2004).

Uno de los ejemplos más comunes de este tipo de causantes de estrés se presenta cuando los hijos de los inmigrantes hispanos alcanzan la adolescencia. Debido a las diferencias propias del proceso de aculturación, los conflictos familiares son más comunes en las familias multigeneracionales y se exacerban cuando los adolescentes comienzan a estar más involucrados en actividades con los miembros de la sociedad de residencia. Lo mismo ocurre cuando quieren hablar solamente en inglés con los miembros de su familia (Sciarra y Ponterotto, 1991). De la misma manera, Ramirez y Hosch (1991) encontraron que los adolescentes latinos con muy poco apego a los valores culturales y las tradiciones hispanas tienden a experimentar más disfunciones familiares. Asimismo, estos investigadores encontraron que niveles favorables de funcionamiento familiar están asociados con la práctica y el apego a los valores y tradiciones hispanas entre los adolescentes. Otros estudios sobre adolescentes han mostrado que quienes han establecido fuertes lazos familiares tienen menos probabilidades de involucrarse en actividades y ambientes perjudiciales para ellos (Stanton-Salazar, coord., 2001; Zhou y Bankston, coords., 1998).

Por su parte, los estresantes instrumentales y ambientales, se relacionan directamente con los bienes y servicios necesarios para la vida cotidiana (empleo, vivienda, la capacidad de comunicarse en inglés y el acceso a los servicios de salud y la educación). Uno de los estresantes más comunes de este tipo se relaciona con la fluidez que los inmigrantes tienen para expresarse en inglés. Estudios en varios países han mostrado que el hecho de no poder hablar la lengua de la sociedad receptora es en sí misma una causa de mucho estrés y frustración (Akiyama, 1996).

En este contexto, algunos de los elementos identificados como factores de riesgo ligados al estrés ambiental están asociados con las dificultades que los inmigrantes experimentan ante la falta de fluidez en la lengua y las diferencias intergeneracionales en el nivel de aculturación entre los padres indocumentados y sus hijos, quienes son ciudadanos estadunidenses. A su vez, otros estudios han revelado que los desafíos económicos y laborales están relacionados con niveles altos de estrés en los inmigrantes hispanos (Cavazos-Rehg, Zayas y Spitznagel, 2007).

Finalmente, los estresantes sociales se relacionan con el estatus migratorio, el miedo a la deportación y la discriminación. Este último factor de rechazo por parte de la población receptora se evidencia en las diferencias expuestas en el trato hacia los inmigrantes, las distintas formas de prejuicios, la promulgación de leyes cada vez más antinmigrantes, la exclusión, así como el hecho de no ofrecer las mismas oportunidades que se les brindan a los nativos (Araujo y Borrells, 2006). 
Entre los estresantes sociales, el estatus legal es un elemento muy importante en la vida de los inmigrantes indocumentados y los miembros de su familia. Se calcula que los hispanos indocumentados constituyen aproximadamente una quinta parte de los 53 millones de hispanos residentes en Estados Unidos (Pew Hispanic Center, 2012). Otros trabajos han confirmado que algunos de los problemas más frecuentes entre los inmigrantes indocumentados (diferencias culturales, deportaciones y discriminación) intensificarían los niveles de estrés en este grupo, en comparación con los inmigrantes documentados (Perez y Fortuna, 2005; Sullivan y Rehm, 2005). Por ejemplo, para los inmigrantes indocumentados, la separación de su familia es un factor que incrementa el nivel de estrés aculturativo (Arbona et al., 2010). A su vez, los hispanos indocumentados mencionaron que ellos reciben menos apoyo familiar cuando se los compara con el grupo de inmigrantes documentados (Perez y Fortuna, 2005).

Derivado de esta visión global, el término estrés aculturativo ha sido usado para describir los problemas y desafíos que experimentan los inmigrantes en el proceso de aculturación, que está inversamente relacionado con su salud física y emocional (Berry y Uichol, 1988). Entre los síntomas más comunes relacionados con este tipo de estrés se encuentran los sentimientos de aislamiento, rechazo, conflictos de identidad, ansiedad, enfermedades psicosomáticas y depresión (Williams y Berry, 1991). De acuerdo con la teoría cognitiva del estrés, los inmigrantes son más propensos a experimentar niveles altos de estrés cuando están envueltos en circunstancias o sucesos incontrolables, sabedores de que éstos tendrán efectos negativos en su bienestar individual y familiar (Folkman et al., 1986). Evidencia empírica sugiere que el estrés aculturativo está asociado con las demandas del contexto social en Estados Unidos; por ende, los inmigrantes hispanos, quienes son incapaces de manejar los conflictos interculturales, tienen más probabilidades de fracasar en los ajustes que deben realizar (Torres y Rollock, 2004). La misma situación ocurre con los grupos minoritarios de inmigrantes que experimentan más estrés aculturativo cuando su cultura de origen tiene pocas similitudes con la cultura de residencia (Berry, 1980).

Ciertos trabajos se han realizado para identificar la relación entre el estrés aculturativo y ciertos factores, por ejemplo, Hovey (2000) encontró que los inmigrantes mexicanos con disfunciones familiares, bajos recursos socioeconómicos y en la circunstancia de estar separados de su familia eran más propensos a reportar niveles altos de estrés aculturativo. No sólo la separación familiar tiene consecuencias negativas para los migrantes, sino también experiencias como la pérdida significativa de los lazos familiares, un sentimiento de profunda nostalgia, el verse impedidos de la posibilidad de regresar a sus comunidad de origen ante la muerte o enfermedad de un ser querido, el desprenderse de sus raíces culturales, así como la incertidumbre de no 
saber si algún día regresarán a su tierra, factores que se han descrito muy claramente dentro del concepto de duelo migratorio (Gonzalez, 2005).

De la misma manera, variables como la falta de cohesión familiar, el uso del español como lengua nativa y los pocos años de residencia en Estados Unidos son causas de estrés aculturativo en los inmigrantes provenientes de distintos países de América Latina (Miranda y Matheny, 2000). La misma tendencia se encontró en las familias hispanas, en las que las diferencias en el nivel de aculturación entre los adolescentes y sus padres precipitaron la presencia de estrés aculturativo (Hernandez y McGoldrick, 1999). Así es como los inmigrantes experimentan diferentes niveles de estrés aculturativo, dependiendo de los recursos que tienen para enfrentar los desafíos y obstáculos propios del proceso de aculturación (Folkman et al., 1986).

Además de las condiciones económicas, el funcionamiento familiar y las características internas de los inmigrantes, el estatus legal es otro factor asociado directamente con la presencia del estrés aculturativo. Debido a los riesgos que conlleva la adaptación a una nueva cultura, el estatus de indocumentado es un factor muy común relacionado con el estrés aculturativo. Diversos estudios han mostrado que los inmigrantes indocumentados que viven en Canadá y Estados Unidos tienen más probabilidades de sufrir la falta de apoyo al vivir lejos de su familia nuclear, tener poca fluidez en el inglés y conservar valores muy tradicionales respecto de los roles de género y el funcionamiento familiar. Estos factores en conjunto los vuelven susceptibles de reportar niveles más altos de estrés aculturativo en comparación con los inmigrantes documentados (Arbona et al., 2010; Perez y Fortuna, 2005; Simich, 2006).

Al respecto, Cavazos-Rehg, Zayas y Spitznagel (2007) afirman que el estatus de indocumentado es un factor estresante, muy grave y persistente entre los inmigrantes hispanos, lo que incrementa su vulnerabilidad a sufrir diversos problemas emocionales y socioculturales, incluyendo el estrés aculturativo. Por otro lado, otros estudios han revelado que los inmigrantes hispanos experimentan niveles altos de estrés, ansiedad y disfunciones familiares a raíz de la gran cantidad de deportaciones y la reciente aprobación y ejecución de un gran número de leyes antinmigrantes (Rodriguez y Hagan, 2004). De igual manera, los inmigrantes indocumentados reportaron niveles más bajos de apoyo familiar que los documentados (Perez y Fortuna, 2005). En contraste, no sólo la aceptación y hospitalidad de los miembros de la sociedad de residencia están directamente relacionadas con el aumento en la autoestima de los inmigrantes, sino que también es cierto que quienes son capaces de establecer relaciones significativas y cercanas con los miembros de la nueva cultura reportaron índices más bajos de estrés aculturativo (Kealey, 1989; Vega, Kolody, Valle y Weir, 1991). 


\section{ADAPTACIÓN PSICOLÓGICA, RECURSOS Y ESTRATEGIAS DE SUPERACIÓN}

Frente a un panorama como el ya descrito, pareciera que los inmigrantes hispanos residentes en Estados Unidos tendrían nulas oportunidades de salir avantes en su proceso de adaptación. Sin embargo, ellos cuentan con numerosos recursos y estrategias de acción, entre los que destacan el apoyo familiar, los centros comunitarios hispanos, los servicios gratuitos de Medicaid, la ayuda financiera que reciben los hijos de inmigrantes que nacen en Estados Unidos, los programas de prevención y atención diseñados directamente para los hispanos, los servicios consulares que cada país latinoamericano ofrece, así como la ayuda de distinta índole que proveen las ONG a familias de bajos recursos.

Estos recursos a su disposición les permiten no sólo responder a las nuevas condiciones imperantes en Estados Unidos, sino también alcanzar, gradualmente, cada una de las expectativas que un día los motivaron a dejar sus países de origen. Para lograr este cometido, la adaptación psicológica es un elemento clave en el largo y sinuoso proceso de aculturación. Muchos autores han descrito que esta adaptación se caracteriza por el desarrollo de estrategias de superación, cambios significativos en el estilo de vida y la presencia de interacciones sociales significativas. Cada uno de estos factores, que a su vez reciben influencias por las condiciones económicas, sociales e individuales de cada quien, presentes en el país receptor, son determinantes para facilitar la correcta adaptación de los inmigrantes (Ward, 2004).

En términos generales, la adaptación psicológica se considera un proceso de aprendizaje caracterizado por la percepción subjetiva que cada individuo tiene respecto de su propio bienestar y concepto de felicidad. El principal objetivo de este tipo de adaptación es adquirir un nuevo repertorio de conductas, que los inmigrantes empleen en la nueva cultura (Negy y Woods, 1992). De acuerdo con Berry, la adaptación psicológica se define como un conjunto de rasgos psicológicos internos que incluyen un sentido claro de identidad cultural y personal, una buena salud mental y el logro personal en el nuevo contexto cultural (Berry, 1997).

A su vez, la adaptación psicológica hace posible que los individuos hagan una evaluación positiva de las circunstancias en las que viven y de su propia realización. Se ha encontrado que la adaptación psicológica influye directamente en las percepciones de los individuos. Así, quienes se perciben como valiosos y satisfechos son capaces de enfrentar de mejor manera las situaciones estresantes más comunes (Neto, 2002).

Como hemos señalado en este trabajo, por medio del proceso de aculturación los inmigrantes ajustan sus vidas a la sociedad receptora, con la finalidad de conseguir una adaptación exitosa a la nueva cultura. Mientras que, para algunos inmigrantes, 
este proceso les lleva solamente unos cuantos días, otros pueden tardar varios años en conseguir este objetivo (Berry, 1997). Aunque los primeros cambios son por lo general negativos y perturbadores, después de un periodo, la mayoría de los inmigrantes comienzan a experimentar una adaptación psicológica favorable a la nueva cultura (Beiser et al., 1988). Para conseguirla en su totalidad, los recursos personales y sociales con que cuentan los inmigrantes, así como las estrategias de superación que ellos desarrollan desde que salen de sus países de origen, serán determinantes para lograr una adaptación satisfactoria.

De manera particular, en el proceso psicológico que conlleva aclimatarse a un nuevo país, la mayoría de los latinos considera que la familia es por sí misma uno de los principales recursos en esta nueva aventura. Hay quienes han usado el término familism para enfatizar la importancia de la familia en la cultura hispana (Cooley, 2001; Cortes, 1995; Parra-Cardona et al., 2006; Sabogal et al., 1987). "Familism" se utiliza para referirse a los sentimientos de solidaridad, lealtad, respeto y reciprocidad compartidos por los miembros de una familia. Dicho término también incluye la noción de que la familia es una de las características más permanentes y distintivas que un individuo posee (Contreras et al., 1999; Sabogal et al., 1987). Como han demostrado los resultados en un sinfín de estudios, la familia es para la mayoría de los latinos un recurso muy importante, ya que conlleva un profundo sentido de bienestar y les permite, al mismo tiempo, sentirse íntimamente arraigados a sus raíces familiares (Parra-Cardona et al., 2006).

Entre los efectos positivos asociados a la convivencia familiar, Gil, Wagner y Vega (2000) encontraron que estar inmersos en la familia es un fuerte protector en contra del estrés aculturativo. Asimismo, otros estudios revelan que el estatus generacional y la exposición al ambiente cultural presente en la sociedad de residencia son factores muy importantes relacionados con el apego familiar (Mindel, 1980; Sabogal et al., 1987). Aunque es más difícil para las familias inmigrantes de origen mexicano mantener altos niveles de cercanía familiar, ya que varios de los miembros de la familia tienen más de un empleo y, por ende, es poco el tiempo que pasan juntos, estos inmigrantes continúan enfatizando la importancia de la familia en su adaptación a la cultura estadunidense (Bacallao y Smokowski, 2007).

No sólo la familia es determinante para una aculturación satisfactoria; también el apoyo social se considera uno de los recursos más importantes que los inmigrantes reciben en este proceso. Debido a la pérdida de un contacto cercano y continuo con familiares y amigos, muchas veces los inmigrantes tienen más dificultades para conseguir el apoyo social que necesitan. De hecho, la mayoría de los inmigrantes pertenecientes a grupos minoritarios reciben y se benefician solamente del apoyo social que ofrecen los miembros de sus mismos grupos étnicos (Turney y Kao, 2009). 
Por el contrario, los inmigrantes experimentan mejores condiciones de vida cuando tienen una red social de amigos y familiares previamente establecidos en el nuevo país de residencia (Massey, 1999). De igual modo, la capacidad para establecer fuertes lazos con los miembros de la familia o amigos que ya se encuentran viviendo en la sociedad receptora es un apoyo decisivo para lograr una adaptación más sencilla.

En este contexto, el apoyo social es considerado uno de los recursos más significativos para los inmigrantes y sus hijos (Harknett, 2006; Henly et al., 2005; Ryan, Kalil y Leininger, 2009). Ciertos análisis sobre esta área, cuyo objetivo es examinar variables muy concretas, han revelado que, en las familias de bajos recursos económicos, el apoyo social es determinante para enfrentar los obstáculos de la vida cotidiana y reducir la probabilidad de vivir por debajo del nivel de pobreza (Henly et al., 2005). Turney y Kao (2009) señalan que este apoyo incluye la obtención de recursos financieros y emocionales (ayuda para pagar la vivienda, dinero en efectivo, consejos y el cuidado de los hijos).

Por otra parte, la importancia del apoyo social se asocia con la presencia o ausencia de lazos familiares, incluyendo a los miembros de la familia extendida, quienes proveen todo tipo de apoyo cuando es necesario (Glick y van Hook, 2002).

También se ha demostrado una relación directa entre el apoyo familiar y la salud de los hijos de inmigrantes. Por ejemplo, Sherraden y Barrera (1997) encontraron que las madres inmigrantes mexicanas que recibieron más apoyo familiar fueron menos propensas a tener bebés de bajo peso que las madres con un apoyo familiar muy limitado. De igual manera, otros estudios mostraron una relación positiva entre la salud de los niños y el apoyo financiero y emocional que reciben las familias hispanas (Kanaiaupuni et al., 2005). El mismo patrón se encontró en adolescentes pertenecientes a distintos grupos étnicos; por ejemplo, quienes han establecido fuertes lazos familiares tienen menos probabilidades de involucrase en ambientes perjudiciales caracterizados por pandillerismo, tráfico de drogas y delincuencia (Stanton-Salazar, 2001; Zhou y Bankston, 1998).

Aunque la mayoría de las investigaciones que han tenido como objeto de estudio el apoyo social incluyen la participación de afroestadunidenses y estadunidenses de origen europeo, sólo unos cuantos estudios se han centrado en latinos, asiáticos y otros grupos de inmigrantes (Turney y Kao, 2009). En estudios multiculturales cuya finalidad ha sido llenar este vacío en la literatura científica y comparar el apoyo social que reciben distintos grupos étnicos, se han encontrado resultados muy significativos, por ejemplo, Hao (2003) afirmó que los inmigrantes mexicanos tienen más probabilidades de recibir un apoyo social continuo si se les compara con los inmigrantes de origen hindú, japonés o chino. Además, cuando los inmigrantes hispanos requieren 
apoyo emocional y financiero, acuden a sus familiares con más frecuencia que los estadunidenses de origen europeo (Schweizer, Schnegg y Berzborn, 1998).

De la misma manera, los mexicanos que emigraron a Estados Unidos reciben más apoyo financiero por parte de sus familiares que los latinos nacidos en Estados Unidos (Glick, 1999). Por el contrario, los inmigrantes originarios de Asia tienen muchas dificultades para recibir apoyo familiar, debido a la escasez de lazos familiares y a sus valores culturales, los cuales los motivan a ser autosuficientes (Rao et al., 1990).

Por otra parte, respecto de las estrategias de superación, diversos estudios han revelado cómo los inmigrantes intentan establecer relaciones exitosas con los miembros de la sociedad de residencia. En términos generales, esas estrategias se relacionan con los esfuerzos cognitivos y conductuales que los individuos desarrollan para contener el impacto del estrés al que están expuestos (Terry, 1994). Estas estrategias de superación se relacionan con niveles altos de funcionamiento familiar e individual en la mayoría de los grupos étnicos que conviven en Estados Unidos.

Así pues, los individuos con estrategias proactivas de superación tienen más probabilidades de conseguir las metas que se proponen en la vida, tener iniciativa propia y aprender de sus propios errores y aciertos (Tyler, Brome y Williams, 1991). A su vez, cuando los inmigrantes son capaces de adquirir y desarrollar estrategias y habilidades basadas en sus valores, tradiciones y experiencias, ellos tienen más probabilidades de salir adelante en los desafíos propios del proceso de inmigración (Hobfoll, 1998).

Aunque las estrategias de superación se clasifican de acuerdo con diferentes criterios, cabe distinguir claramente entre las basadas en las emociones y las basadas en los problemas. Las estrategias basadas en las emociones se utilzan frecuentemente para reducir el nivel de estrés emocional al cual uno está expuesto. Este tipo facilita la expresión de sentimientos, tensiones y frustraciones, así como la práctica del autocontrol.

Por otra parte, las estrategias orientadas en los problemas se han considerado un recurso muy significativo, por medio del cual es posible recibir el apoyo de las personas de nuestro entorno, desarrollar un estilo de comunicación receptivo y manejar el estrés (Folkman y Lazarus, 1991). En algunos trabajos se ha encontrado que las estrategias orientadas en los problemas se relacionan con la solución exitosa de situaciones muy complejas, así como la posibilidad de lograr una adaptación satisfactoria (Billings y Moos, 1981; Holahan y Moos, 1987; Schmitz, 1992).

Finalmente, el idioma es otra estrategia de superación que ha influido en el funcionamiento familiar de los latinos residentes en Estados Unidos. Por otro lado, otros estudios han revelado cambios significativos en las familias de inmigrantes hispanos en la primera, segunda, tercera y cuarta generación. Por ejemplo, la primera generación de latinos crece frecuentemente en un hogar donde los padres y los hijos se comu- 
nican sobre todo en español. Sin embargo, aunque la segunda generación recibe influencia del aprendizaje del inglés que adquieren en las escuelas estadunidenses, estos niños continúan hablando español con sus padres (Buriel, 1993).

A su vez, Portes y Hao (2002) encontraron una relación positiva entre el bilingüismo y la adaptación psicosocial de la segunda generación de inmigrantes. Ellos encontraron esta conexión al comparar a los hijos de inmigrantes totalmente bilingües con quienes son parcialmente bilingües o monolingües. En estos estudios se concluye que aprender las dos lenguas les permite comunicarse con sus familiares en español y, al mismo tiempo, poder hablar en inglés con los ciudadanos estadunidenses. De ahí la importancia de esta estrategia de superación, la cual les abre las puertas de un mejor porvenir en el plano laboral y en el académico.

\section{CONCLUSIONES}

En este artículo ha quedado de manifiesto que el fenómeno de la migración es un tema fascinante debido a la complejidad y riqueza que conlleva. La historia de la migración en Estados Unidos da cuenta del predominio y los aportes tan significativos de la comunidad hispana a lo largo de las últimas cuatro décadas. Como se dijo repetidas veces, la decisión de abandonar sus países de origen, con la incertidumbre de no saber si algún día regresarán a su tierra natal, conlleva sentimientos de nostalgia, miedo, desánimo y tristeza; sin embargo, la inmensa mayoría de los inmigrantes hispanos emprende ese viaje cargados de ilusiones y esperanzas.

En esta revisión se mostró que más allá de encontrar una mejor situación económica para sí mismos y un mejor porvenir para sus hijos, la mayoría de los migrantes enfrentan una gran cantidad de obstáculos y desafíos, con efectos directos en su proceso de aculturación. Específicamente, ciertos factores como la explotación laboral, las largas jornadas de trabajo, el bajo nivel educativo, las recientes leyes totalmente antinmigrantes y, sobre todo, el estrés aculturativo, son determinantes para entender las vicisitudes por las que pasan la mayoría de los inmigrantes de origen latino. Estas condiciones son aún peores para las mujeres, quienes además de verse en la necesidad de sumarse a la fuerza laboral, tienen que desempeñar todas las labores domésticas y, en particular, la crianza de sus hijos.

Aun cuando en primera instancia pareciera que el proceso de aculturación es siempre cuesta arriba, los latinos cuentan con innumerables recursos que les permiten enfrentar estas adversidades. Como se señaló en el último apartado, la importancia de los lazos familiares, el apoyo de amigos y familiares que ya residen en Estados Unidos, las estrategias de superación, los recursos gubernamentales y la educación que 
reciben sus hijos son determinantes no sólo para alcanzar sus metas personales y decir que valió la pena abandonar o dejar atrás a los suyos en su tierra natal, sino también para sentirse satisfechos de su nueva vida en este país. Por su tenacidad y valentía, es imprescindible reconocer y elogiar todo el esfuerzo que día a día hacen los mujeres y los hombres hispanos, cuyo único objetivo es aportar lo mejor de sí mismo al país que los recibió, además de crear las condiciones más apropiadas para el desarrollo y bienestar de sus hijos.

\section{FUENTES}

Adelman, Mara

1988 "Cross-cultural Adjustment: A Theoretical Perspective on Social Support", International Journal of Intercultural Relations, vol. 12, pp. 183-204.

AKIYAMA, TSUYOSHI

1996 "Onset Study of English Speaking Temporary Residents in Japan", Social Psychiatry and Psychiatry Epidemiology, vol. 31, no. 3, pp. 194-198.

AL-ISSA, IHSAN

1997 "Ethnicity, Immigration, and Psychopathology", en Al-Issa, Ihsan et al., eds., Ethnicity, immigration, and psychopathology, Nueva York, Plenum, pp. 3-16.

Araujo, Beverly y Luisa Borrells

2006 "Understanding the Link Between Discrimination, Mental Health Outcomes and Life Chances among Latinos", Hispanic Journal of Behavioral Sciences, vol. 28, pp. 245-266.

Arbona, Consuelo et al.

2010 "Acculturative Stress among Documented and Undocumented Latino Immigrants in The United States", Hispanic Journal of Behavioral Sciences, vol. 32, no. 3, pp. 362-384.

Aspe, Pedro, coord.

1993 El camino mexicano de la transformación económica, México, FCE. 
Bacallao, Martica y Paul Smokowski

2007 "The Costs of Getting Ahead: Mexican Family System Changes after Immigration", Family Relations, vol. 56, pp. 52-66.

BEISER, MARK et al., comps.

1988 Mental Health Issues Affecting Immigrants and Refugees, Ottawa, Health and Welfare Canada.

BERRY, JOHN

2001 "A Psychology of Immigration", Journal of Social Issues, vol. 57, pp. 615-631.

1997 "Immigration, Acculturation, and Adaptation", Applied Psychology: An International Review, vol. 46, no. 1, pp. 5-68.

1980 "Acculturation as Varieties of Adaptation", en Arturo Padilla, ed., Acculturation: Theory, Models, and Some New Findings, Boulder, Westview, pp. 9-25.

BERRY, JOHN et al.

1989 "Acculturation Attitudes in Plural Societies", Applied Psychology: An International Review, vol. 38, pp. 185-206.

1987 “Comparative Studies of Acculturative Stress", International Migration Review, vol. 21, 491-511.

BERRY, JOHN Y KIM UICHOL

1988 "Acculturation and Mental Health", en Pierre Dasen et al., eds., Health and Cross-Cultural Psychology: Towards Applications, Londres, Sage, pp. 207-236.

BHUGRA, DiNESH

2004 "Migration and Mental Health", Acta Psychiatrica Scandinavica, vol. 109, pp. 243-258.

Billings, Andrew y Rudolf Moos

1981 "The Role of Coping Responses and Social Resources in Attenuating the Stress of Life Events", Journal of Behavioral Medicine, vol. 4, pp. 139-157.

BOCHNER, STEPHEN

1982 "The Social Psychology of Cross-Cultural Relations", en Stephen Bochner, ed., Cultures in Contact: Studies in Cross-Cultural Interaction, Nueva York, Elmsford, pp. 5-44. 
BONEVA, BONKA e IRENE FRIEZE

2001 "Toward a Concept of a Migrant Personality", Journal of Social Issues, vol. 57, no. 3, pp. 477-491.

Brett, JeAnne, Linda Stroh y AnNe ReILly

1993 "Pulling up Roots in the 1990s: Who's Willing to Relocate?", Journal of Organizational Behavior, vol. 14, pp. 49-60.

Browning, Harley y Rene ZENTENo

1993 "The Diverse Nature of the Mexican Northern Border: The Case of Urban Employment", Frontera Norte, vol. 5, no. 9, pp. 11-31.

BURIEL, RAYMOND

1993 "Childrearing Orientations in Mexican American Families: The Influence of Generation and Sociocultural Factors", Journal of Marriage and the Family, vol. 55, pp. 987-1000.

CAPLAN, SUSAN

2007 "Latinos, Acculturation, and Acculturative Stress: A Dimensional Concept Analysis", Policy, Politics, and Nursing Practice, vol. 8, pp. 93-106.

Carballo, Manuel, coord.

1994 Scientific Consultation on the Social and Health Impact of Migration: Priorities for Research, Ginebra, International Organization for Migration.

CARrillo, Jorge, coord.

1993 Condiciones de empleo y capacitación en las maquiladoras de exportación en México, México, stPs-Colef.

Cavazos-Rehg, Patricia, Luis Zayas y Edward Spitznagel

2007 "Legal Status, Emotional Well-Being and Subjective Health Status of Latino Immigrants", Journal of the National Medical Association, vol. 99, pp. 1126-1131.

Chavez, Leo, Esteban Flores y Marta Lopez

1989 "Migrants and Settlers: A Comparison of Undocumented Mexicans and Central Americans in the United States", Frontera Norte, vol. 1, no. 1, pp. 49-75. 


\section{Coleman, Kevin}

2002 "Latino Electoral Participation and Representation", en Karl Lawrence, ed., Hispanic Americans: Issues and bibliography, Hauppauge, Nova Science, pp. 52-88.

CONTRERAs, JOSEFINA et al.

1999 "Parenting Competence among Latina Adolescent Mothers: The Role of Family and Social Support", Journal of Research on Adolescence, vol. 9, pp. 417-439.

CoOley, Carol

2001 "The Relationship between Familism and Child Maltreatment in Latino and Anglo Families", Child Maltreatment, vol. 6, no. 2, pp. 130-142.

CORTES, DHARMA

1995 "Variations in Familism in Two Generations of Puerto Ricans", Hispanic Journal of Behavioral Sciences, vol. 17, pp. 249-256.

DANIELS, ROGER

2002 Coming to America. A History of Immigration and Ethnicity in American Life, Princeton, NJ, Perennial.

Dion, Karen y Kenneth Dion

2001 "Gender and Cultural Adaptation in Immigrant Families", Journal of Social Issues, vol. 57, no. 3, pp. 511-521.

Durand, Jorge y Patricia Arias

2000 La experiencia migrante: iconografía de la migración México-Estados Unidos, México, Altexto.

Durand, Jorge, Douglas Massey y Rene Zenteno

2001 "Mexican Immigration to the United States: Continuities and Changes", Latin American Research Review, vol. 36, pp. 107-127.

DuSSEL, ENRIQUE

1997 La economía de la polarización. Teoría y evidencia del cambio estructural en el sector manufacturero mexicano (1988-1996), México, Jus-UNAM. 
El Colegio de la Frontera Norte (Colef), Consejo Nacional de Población (Conapo) y Secretaría del Trabajo y Previsión Social (stps)

1994 Encuesta sobre migración en la frontera norte, Mexico, Colef-Conapo-sTPS.

EsPIN, OLIVA

1987 "Psychological Impact of Migration on Latinas: Implications for Psychotherapeutic Practice", Psychology of Women Quarterly, vol. 4, no. 11, pp. 489-503.

Fassmann, Heinz y Rainer Munz

1994 European Migration in the Late Twentieth Century: Historical Patterns, Actual Trends, and Social Implications, Luxemburgo, International Institute for Applied Systems Analysis.

FOLKMAN, SUSAN et al.

1986 "Dynamics of a Stressful Encounter: Cognitive Appraisal, Coping, and Encounter Outcomes", Journal of Personality and Social Psychology, vol. 50, pp. 992-1003.

FolKMAn, SUSAN y Richard Lazarus

1991 "Coping and Emotion", en Alan Monat y Richard Lazarus, eds., Stress and Coping: An Anthology, Nueva York, Columbia University Press, pp. 207-227.

Frieze, Irene, Susan Hansen y Bonka Boneva

2006 "The Migrant Personality and College Students' Plans for Geographic Mobility", Journal of Environmental Psychology, vol. 26, pp. 170-177.

Garcia, Carolyn y SAndi Lindgren

2009 "Life Grows between the Rocks: Latino Adolescents' and Parents' Perspectives on Mental Health Stressors", Research in Nursing \& Health, vol. 32, pp. 148-162.

GeORGE, Usha y SARAH RAmKISSOON

1998 "Race, Gender, and Class: Interlocking Oppressions in the Lives of South Asian Women in Canada", Affilia Journal of Women and Social Work, vol. 13, no. 1, pp. 102-120.

Gil, Andres, Eric Wagner y William Vega

2000 "Acculturation, Familism, and Alcohol Use among Latino Adolescent Males: Longitudinal Relations", Journal of Community Psychology, vol. 28, pp. 443-458. 
GLICK, JENNIFER

1999 "Economic Support from and to Extended Kin: A Comparison of Mexican Americans and Mexican Immigrants", International Migration Review, vol. 33, no. 3, pp. 745-765.

GLick, JENNIFER y JeNnifer VAn HoOK

2002 "Parents' Coresidence with Adult Children: Can Immigration Explain Racial and Ethnic Variation?", Journal of Marriage and the Family, vol. 64, no. 1, pp. 240-253.

GonZAlez, ARTuRO, coord.

2002 Mexican Americans and the U.S. Economy: The Mexican American Experience, Tucson, The University of Arizona Press.

GONZALEZ, JuAN, coord.

2000 Harvest of Empire: A History of Latinos in America, Nueva York, Viking Penguin.

GONZÁlEZ, VALENTíN

2005 "El duelo migratorio", Trabajo Social, vol. 7, pp. 77-97.

HÄMÄLÄINEN, KARI

2002 "Unemployment, Selective Employment Measures and Inter-regional Mobility of Labor", Papers in Regional Science, vol. 81, pp. 423-441.

HAO, LINGXIN

2003 "Immigration and Wealth Inequality in the U.S.", Nueva York, Russel Sage Foundation (Working Paper, no. 202).

HARKNETT, KRISTEN

2006 "The Relationship between Private Safety Nets and Economic Outcomes among Single Mothers", Journal of Marriage and Family, vol. 68, pp. 172-191.

Henly, Julia, Sandra Danziger y Shira Offer

2005 "The Contribution of Social Support To The Material Well-Being of Low-Income Families", Journal of Marriage and Family, vol. 67, pp. 122-140.

Hernandez, Miguel y Monica McGoldrick

1999 "Migration and the Family Life Cycle", en Betty Carter y Monica McGoldrick, 
eds., The Expanded Family Life Cycle: Individual, Family, And Social Perspectives, Needham Heights, Allyn and Bacon, pp. 169-173.

Hewstone, Miles y Rupert Brown, comps.

1986 Contact and Conflict in Intergroup Encounters, Oxford, Basic Blackwell.

HobFoll, Stevan, coord.

1998 Stress, Culture, and Community: The Psychology and Philosophy of Stress, Nueva York, Plenum Press.

Hoefer, Michael, Nancy Rytina y Bryan Baker

2012 "Estimates of the Unauthorized Immigrant Population Residing in the United States: January 2011", DHS Office of Immigration Statistics, pp. 1-7.

Holahan, Charles y Rudolf Moos

1987 "Personal and Contextual Determinants of Coping Strategies", Journal of Personality and Social Psychology, vol. 52, pp. 946-955.

Hondagneu-Sotelo, Pierrette, coord.

2001 Domestica: Immigrant Workers Cleaning and Caring in the Shadows of Affluence, Berkeley, University of California Press.

HORENCZYK, GABRIEL

1996 "Migrant Identities in Conflict: Acculturation Attitudes and Perceived Acculturation Ideologies", en Glynis Breakwell y Evanthia Lyons, eds., Changing European Identities: Social Psychological Analyses of Social Change, Oxford, Butterworth-Heinemann, pp. 241-250.

HoveY, JosepH

2000 "Psychosocial Predictors of Acculturative Stress in Mexican Immigrants", Journal of Psychology, vol. 134, pp. 480-502.

IBARRA, MARIA DE LA LuZ

2000 "Mexican Immigrant Women and the New Domestic Labor", Human Organization, vol. 5, pp. 452-464. 
KanAiAupuni, SHAWn et al.

2005 "Counting on Kin: Social Networks, Social Support, and Child Health Status", Social Forces, vol. 83, no. 3, pp. 1137-1164.

KeAley, DANIEL

1989 "A Study of Cross-Cultural Effectiveness: Theoretical Issues and Practical Applications", International Journal of Intercultural Relations, vol. 13, pp. 387-428.

Kosic, ANKICA

2004 "Acculturation Strategies, Coping Process, and Acculturative Stress", Scandinavian Journal of Psychology, vol. 45, 269-278.

2002 "Acculturation Attitudes, Need for Cognitive Closure, and Adaptation of Immigrants", The Journal of Social Psychology, vol. 142, no. 2, pp. 179-201.

LaZARUS, Richard y SUSAN FolKMAN, coords.

1984 Stress, Appraisal, and Coping, Nueva York, Springer.

Light, Ivan, Parminder Bhachu y Stavros Karageorgis

1993 "Migration Networks and Immigrant Entrepreneurship, en Ivan Light y Parminder Bhachu, eds., Immigration and Entrepreneurship: Culture, Capital, and Ethnic Networks, , Nueva Brunswick, Transaction, pp. 25-50.

LIN, JAN

1995 "Polarized Development and Urban Change in New York's Chinatown", Urban Affairs Review, vol. 30, pp. 332-354.

Massey, Douglas

1999 "Why Does Immigration Occur? A Theoretical Synthesis", en Charles Hirschman et al., eds., The Handbook of International Migration: The American Experience, Nueva York, Russell Sage Foundation, pp. 34-52.

1995 "The New Immigration and Ethnicity in the United States", Population and Development Review, vol. 21, no. 3, pp. 631-652.

Maydell-Stevens, Elena, Anne-Marie Masgoret y Tony Ward

2007 "Problems of Psychological and Sociocultural Adaptation among Russianspeaking Immigrants in New Zealand", Social Policy Journal of New Zealand, vol. 30, pp.178-198. 
Melville, Margarita

1978 "Mexican Women Adapt to Migration", International Migration Review, vol. 12, no. 2, pp. 225-235.

\section{Mindel, CHARLES}

1980 "Extended Familism among Urban Mexican Americans, Anglos, and Blacks", Hispanic Journal of Behavioral Sciences, vol. 2, pp. 21-34.

Miranda, Alexis y Kenneth Matheny

2000 "Socio-Psychological Predictors of Acculturative Stress among Latino Adults", Journal of Mental Health Counseling, vol. 22, pp. 306-317.

Moghaddam, Fathali, Donald Taylor y Richard Lalonde

1987 "Individualistic and Collective Integration Strategies among Iranians in Canada", International Journal of Psychology, vol. 22, pp. 301-313.

Morrison, Peter y Judith Wheeler, coords.

1976 The Image of Elsewhere in the American Tradition of Migration, Santa Monica, RAND Corporation.

Negy, Charles y Donald Woods

1992 "The Importance of Acculturation in Understanding Research with Hispanic-Americans", Hispanic Journal of Behavioral Sciences, vol. 14, pp. 224 - 247.

Neto, FELIX

2002 "Social Adaptation Difficulties of Adolescents with Immigrant Backgrounds", Social Behavior and Personality, vol. 30, no. 4, pp. 335-346.

Oudenhoven, Jan van, Grace Willemsma y Kristen Prins

1996 "Integration and Assimilation of Moroccans, Surinamers, and Turks in the Netherlands", De Psycholoog, vol. 31, pp. 468-478.

PARRA-CARDONA, Jose, et al.

2006 "Trabajando duro todos los días: Learning from the experiences of Mexicanorigin migrant families", Family Relations, vol. 55, pp. 361-375. 
Parrado, Emilio y Chenoa Flippen

2005 "Migration and Gender among Mexican Women", American Sociological Review, vol. 70, pp. 606-632.

PASSEL, JEFFREY

2005 "Estimates of the Size and Characteristics of the Undocumented Population", en <http: / / pewhispanic.org/files / reports / 44.pdf>, consultada el 9 de enero de 2013.

PÉrez, CARMela y Lisa Fortuna

2005 "Psychosocial Stressors, Psychiatric Diagnosis, and Utilization of Mental Health Services among Undocumented Immigrant Latinos", Journal of Immigrant and Refugee Services, vol. 3, pp. 107-123.

\section{Pew Hispanic Center}

2012 Statistical Portrait of Hispanics in the United States, Pew Hispanic Center, Washington, DC.

2009 A Portrait of Unauthorized Immigrants in the United States, Washington, DC. Pew Hispanic Center.

Phinney, JEAN

1990 "Ethnic Identity in Adolescents and Adults Review of Research", Psychological Bulletin, vol. 3, no. 108, pp. 499-514.

Portes, Alejandro y Lingxin Hao

2002 "The Price of Uniformity: Language, Family, and Personality Adjustment in the Immigrant Second Generation", Ethnic and Racial Studies, vol. 25, pp. 889-912.

Portes, Alejandro y Ruben Rumbaut, coords.

1996 Immigrant America: A Portrait, $2^{\mathrm{a}}$ ed., Berkeley, University of California Press.

Purdum, TOOD

2000 "Shift in the Mix Alters the Face of California", en <http: / / www.nytimes. com / 2000/07/04/us / shift-in-the-mix-alters-the-face-of-california.html? pagewanted $=1>$, consultada el 25 de diciembre de 2011 . 
QuesADA, JAMES

1999 "From Central American Warriors to San Francisco Latino Day Laborers: Suffering and Exhaustion in a Transnational Context", Transforming Anthropology, vol. 81,pp. 162-185.

Ramírez, Jorge y Harmon Hosch

1991 The Influence of Acculturation on Family Functioning among Hispanic Americans in a Bicultural Community, Temple, Arizona, ponencia presenta en la Biennal Conference on Community Research and Action.

Rao, Nandini, Prakasa Rao y Marilyn Fernández

1990 "An Exploratory Study of Social Support among Asian Indians in the U.S.A", International Journal of Contemporary Sociology, vol. 27, no. 3-4, pp. 229-245.

Redfield, Robert, Ralph Linton y Melville Herskovits

1936 "Memorandum for the Study of Acculturation", American Anthropologist, vol. 38, pp. 149-152.

Rivera-BATIZ, Francisco

1999 "Undocumented Workers in the Labor Market: An Analysis of the Earnings of Legal and Illegal Mexican Immigrants in the United States", Journal of Population Economics, vol. 12, pp. 91-116.

Rodriguez, Nestor y Jaceueline Hagan

2004 "Fractured Families and Communities: Effects of Immigration Reform in Texas, Mexico, and El Salvador", Latino Studies, vol. 2, pp. 328-351.

\section{RÖNSTRÖM, ANITHA}

1989 "Children in Central America: Victims of War", Child Welfare, vol. 68, no. 2, pp. 145-153.

Rumbaut, Ruben

1994 "Origins and Destinies: Immigration to the United States since World War II", Sociological Forum, vol. 9, no. 4, pp. 583-621.

Ryan, Rebecca, Ariel Kalil y Lindsey Leininger

2009 "Low-Income Mothers' Private Safety Nets and Children's Socioemotional Well-Being", Journal of Marriage and Family, vol. 71, pp. 278-297. 
SABOGAL, FABIO et al.

1987 "Hispanic Familism and Acculturation: What Changes and What Doesn't?", Hispanic Journal of Behavioral Sciences, vol. 9, pp. 397-412.

SAKKEUS, LUULE

1994 "The Baltic States", en Solon Ardittis, ed., The Politics of East-West Migration, Londres, Macmillan, pp. 32-47.

SCHMITZ, PAUL

1992 "Immigrant Mental and Physical Health", Psychology and Developing Societies, vol. 4, pp. 117-131.

Schweizer, Thomas, Marissa Schnegg y Susan Berzborn

1998 "Personal Networks and Social Support in a Multi-Ethnic Community of Southern California", Social Networks, vol. 20, pp. 1-21.

\section{Sciarra, Daniel y Joseph Ponterotto}

1991 "Counseling the Hispanic Bilingual Family: Changes to the Therapeutic Process", Psychotherapy, vol. 28, pp. 473-479.

Sherraden, Margaret y Rossana Barrera

1997 “Culturally-protective Health Practices: Everyday Pregnancy Care among Mexican Immigrants", Journal of Multicultural Social Work, vol. 6, nos. 1-2, pp. 93-115.

SHIN, KYUNG

1999 "The Lived Experience of Korean Immigrant Women Acculturating into the United States", Health Care for Women International, vol. 20, pp. 603-617.

SIMICH, LAURA

2006 "Hidden Meanings of Health Security: Migration Experiences and Systemic Barriers to Mental Well-Being among Non-Status Migrants in Canada", International Journal of Migration Health and Social Care, vol. 2, pp.16-27.

SiMON, JULIAN, coord.

1990 The Economic Consequences of Immigration, Nueva York, Basil Blackwell. 
STANTON-SALAZAR, RicARDO, coord.

2001 Manufacturing Hope and Despair: The School and Kin Support Networks of U.S.Mexican Youth, Nueva York, Teachers College Press.

Sullivan, Margaret y Roberta ReHM

2005 "Mental Health of Undocumented Mexican Immigrants: A Review of the Literature", Advances in Nursing Sciences, vol. 28, pp. 240-251.

TERRY, DEBORAH

1994 "Determinants of coping: The Role of Stable and Situational Factors", Journal of Personality and Social Psychology, vol. 66, pp. 895-910.

TORRES, LuCAS y DAVID ROLLOCK

2004 "Acculturative Distress among Hispanics: The Role of Acculturation, Coping, and Intercultural Competence", Journal of Multicultural Counseling and Development, vol. 32, pp. 155-167.

TSENG, WeN, coord.

2001 Handbook of Cultural Psychiatry, Nueva York, Academic Press.

Turney, Kristin y Grace KaO

2009 "Barriers to School Involvement: Are Immigrant Parents Disadvantaged?", The Journal of Educational Research, vol. 102, pp. 257-271.

Tyler, Forrest, Deborah Brome y Janice Williams, coords.

1991 Ethnic Validity, Ecology, and Psychotherapy: A Psychological Competence Model, Nueva York, Plenum Press.

U.S. CENSUS BuREAU

2011 Statistical Abstract of the United States, 2011, Washington, D.C., U.S. Department of Commerce.

2001 Statistical Abstract of the United States, 2001, , Washington, D.C., U.S. Department of Commerce.

1992 Statistical Abstract of the United States: 1992, , Washington, D.C., U.S. Department of Commerce. 


\section{U.S. IMMigration AND NATURALIZATION SERVICE}

1994 Statistical Yearbook of the Immigration and Naturalization Service, 1993, Washington, D.C., US Government Printing Office.

ValenZuela, Abel

2003 "Day-Labor Work", Annual Review of Sociology, vol. 2, pp. 307-333.

2001 "Day Labourers as Entrepreneurs?", Journal of Ethnic and Migration Studies, vol. 2, pp. 335-352.

Vega, William, Bohdan Kolody, Ramon Valle y Judy Weir

1991 "Social Networks, Social Support, and Their Relationship to Depression among Immigrant Mexican Women", Human Organization, vol. 50, pp. 154-162.

\section{Verduzco, Gustavo}

1995 "La migración mexicana a Estados Unidos: recuento de un proceso histórico", Estudios Sociológicos, vol. 39, pp. 573-594.

VerduZCO, GuSTAVO, coord.

2001 La migración mexicana a Estados Unidos: estructuración de una selectividad histórica, México, Conapo.

WaLter, Nicholas et al.

2002 "Social Context of Work Injury among Undocumented day Laborers in San Francisco", Journal of General Internal Medicine, vol. 17, pp. 221-229.

\section{WARD, COLLEEN}

2004 "Psychological Theories of Culture Contact and their Implications for Intercultural Training and Interventions", Dan Landis et al., eds., Handbook of Intercultural Training, Thousand Oaks, Sage, , pp. 185-216.

Ward, Colleen y Antony Kennedy

1994 "Acculturation Strategies, Psychological Adjustment, and Sociocultural Competence During Cross-Cultural Transitions", International Journal of Intercultural Relations, vol. 18, pp. 329-343.

Williams, Colin y Jan Windebank, coords.

1998 Informal Employment in the Advanced Economies: Implications for Work and Welfare, Nueva York, Routledge. 
Williams, Carolyn y JoHn Berry

1991 "Primary Prevention of Acculturative Stress among Refugees", American Psychologist, vol. 46, pp. 632-641.

WiLSON, WiLLIAM, coord.

1996 When Work Disappears: The World of the New Urban Poor, Nueva York, Alfred A. Knopf.

YeH, Christine et al.

2003 "The Cultural Adjustment and Mental Health of Japanese Immigrant Youth", Adolescence, vol. 38, pp. 481-496.

Zheng, Xue y John Berry

1991 "Psychological Adaptation of Chinese Sojourners in Canada", International Journal of Psychology, vol. 26, pp. 451-470.

ZhOU, Min y CARL BANKSTON, coords.

1998 Growing Up American: How Vietnamese Children Adapt to Life in the United States, Nueva York, Russell Sage Foundation.

ZOLBERG, ARISTIDE, coord.

2006 A Nation by Design: Immigration Policy in the Fashioning of America, Nueva York, Russell Sage Foundation. 